\title{
PORTUGUÊS COMO SEGUNDA LÍNGUA: A ESCRITA DE SURDOS EM APRENDIZAGEM COLETIVA
}

\section{PORTUGUESE AS A SECOND LANGUAGE: THE WRITING OF DEAF PEOPLE IN COLLECTIVE LEARNING}

\author{
Djair Lázaro de Almeida* \\ Cristina Broglia Feitosa de Lacerda**
}

\section{RESUMO}

O presente artigo tem o objetivo de descrever e analisar o processo de escrita em Língua Portuguesa, como segunda língua, desenvolvido por participantes surdos em situação de oficinas. Para tanto se propôs um trabalho de produção textual por meio da reescrita coletiva de uma história de aventura, por confabulações entre pares surdos e educadores ouvintes, tendo a Libras como língua de interlocução. Observou-se a evolução dos participantes surdos na organização da escrita, desde a recuperação da sequência lógica por princípios de coesão e coerência, passando pelo estabelecimento da ordem sintática por adequação verbal de acordo com exigências discursivas e textuais, até o despertar para o uso consciente das preposições e dos adjetivos na resolução de questões de comunicação e de narratividade de seus enunciados. Palavras-chaves: surdez; língua portuguesa e Libras; interação.

\section{ABSTRACT}

The purpose of this article is to describe and analyze the process of writing in Portuguese as a second language developed by deaf participants in workshops. For this, a work of textual production was proposed through the collective rewriting of an adventure story, by confabulations between deaf couples and listening educators, by using Libras as the language of interlocution. It was observed the evolution of deaf participants in the organization of writing, from the recovery of the logical sequence by principles of cohesion and coherence, through the establishment of syntactic order by verbal adequacy according to discursive and textual requirements, until awakening to conscious use of the prepositions and the adjectives in the resolution of questions of communication and of narrativity of its statements.

Keywords: deafness; portuguese language and Libras; interaction.

\section{INTRODUÇÃO}

As questões linguísticas que envolvem as singularidades na aquisição da escrita do aluno surdo suscitam, atualmente, não só o interesse mas também debates

\footnotetext{
* Universidade Federal de São Carlos (UFSCar), São Carlos, SP, Brasil. diair lazaro@yahoo.com.br, http://orcid.org/0000-0002-9999-4206

** Universidade Federal de São Carlos (UFSCar), São Carlos, SP, Brasil. cristinalacerda@uol.com.br, http://orcid.org/0000-0002-3250-1374
} 
no campo da pesquisa educacional. Nas redes de ensino, todavia, a despeito de intenções e estratégias de indivíduos ou grupos que buscam atender o aluno surdo em suas peculiaridades, favorecendo a aprendizagem, desinformações e conceitos inadequados ainda circulam em sala de aula, obstruindo a escolarização plena desses sujeitos. Dentre os aspectos envolvidos nessa escolarização, a leitura e a escrita exigem claras reflexões e fundamentações para desconstruir o entendimento ainda vigente no sistema educacional. Reconhecer que o processo de significação se dá a partir da primeira língua do surdo para a Língua Portuguesa escrita, como segunda língua, é imprescindível para a retomada de posições e consequente correção de inadequações. A aquisição da escrita, imersa no processo de aquisição da linguagem, tem para o surdo um caminho diverso do ouvinte: enquanto este reconstrói a história de sua relação com a linguagem por meio da língua oral, o surdo percorre tal caminho orientando-se pela língua de sinais.

Com efeito, tomando por base a forma de enunciar em Libras, os textos iniciais de alunos surdos trazem as marcas gramaticais da Língua de Sinais. Muito se tem discutido sobre a intolerância de alguns professores em relação a tais marcas, uma vez que esses alunos ancoram na língua de sinais suas enunciações escritas em português. Todavia, cabe ao professor, a partir de um trabalho baseado nas relações interdiscursivas entre as línguas, a sistematização que permite ao aluno surdo alcançar e dominar os processos e modos de enunciar em Língua Portuguesa. O aluno surdo pode sim operar com autonomia a sintaxe do português escrito, desde que provocado e estimulado pelo professor, quando este cria condições favoráveis para o desenvolvimento gramatical e sintático desse aluno na nova língua. Discorrendo sobre um trabalho de sistematização gramatical, Franchi $(1987$, p.42) afirma que é somente manipulando fatos relevantes de sua língua, isto é, fatos carregados de significação, "que o aluno de gramática" poderá construir "hipóteses sobre a natureza da linguagem" e sobre "o caráter sistemático das construções linguísticas", para poder um dia exercitar plenamente uma atividade metalinguística. Isso, conclui o autor, só é possível quando o aluno se familiariza com os fatos da língua, o que decorre da necessidade de sistematizar um saber linguístico que se aprimora conscientemente em torno da significação de mundo, de textos e da linguagem em seus múltiplos recursos de expressão.

Desse modo, o presente artigo tem o objetivo de descrever e analisar o processo de escrita em Língua Portuguesa, como segunda língua, desenvolvido por participantes surdos em situação de oficinas. Para tanto se propôs um trabalho de produção textual por meio da reescrita coletiva de uma história de aventura, por confabulações entre pares surdos e educadores ouvintes, tendo a Libras como 
língua de interlocução. $\mathrm{O}$ processo da reescrita foi colocado neste trabalho como objeto de reflexão sobre as práticas e as formações discursivas que incidiram na aprendizagem dos participantes surdos.

\section{A CONCEPÇÃO BAKHTINIANA DE LINGUAGEM E O PROCESSO DE ENSINO E APRENDIZAGEM}

Para dar suporte às reflexões lançadas neste artigo, tomamos o conceito de língua e linguagem a partir da concepção enunciativo-discursiva de viés bakhtiniano. Assim, interessa-nos o conceito de linguagem como processo de interação verbal, ou seja, a linguagem como lugar de interação humana, de construção de relações sociais e de constituição de sujeitos e, portanto, dialógica. Concebendo a linguagem dessa forma, o processo educativo em relação ao ensino de Língua Portuguesa pode ser conduzido por uma nova abordagem. O que aponta para uma virada discursiva ou enunciativa do trabalho com o texto em sala de aula (ROJO; CORDEIRO, 2010). Assim as autoras se posicionam: "Trata-se então de enfocar, em sala de aula, o texto em seu funcionamento e em seu contexto de produção/leitura, evidenciando as significações geradas mais do que as propriedades formais que dão suporte a funcionamentos cognitivos" (p. 10).

Nesse enfoque, levam-se em conta as circunstâncias ou a situação de produção e de leitura desses textos, direcionando o trabalho em sala de aula para uma leitura interpretativa, reflexiva e crítica, além de apontar para uma atividade de produção textual orientada pelo contexto e por suas finalidades, o que vai além do ensino normativo que prioriza a análise da língua e da gramática $\left(\mathrm{ROJO}_{\text {; }}\right.$ CORDEIRO, 2010). Nesse sentido, o aprendizado da Língua Portuguesa resulta de um movimento de construção fundado nas relações que os sujeitos estabelecem com seus interlocutores, com os fatos e com os acontecimentos, a partir da língua em uso. Ou seja, a apropriação de uma língua se faz por meio da interação verbal, direcionamento esse que enseja a aprendizagem da língua em situação de comunicação, contrariando o ensino que privilegia a análise estritamente gramatical.

A concepção tomada acima pressupõe novas posturas de trabalho educativo, já que a linguagem é lócus de práticas e de atividades que implicam o funcionamento da língua em situação de comunicação, rompendo os liames estabelecidos de língua apenas como código linguístico. Assim, uma língua não é assimilada em seu sistema abstrato, mas a partir da estrutura concreta da enunciação, ou seja, uma língua é assimilada graças aos enunciados concretos utilizados e reproduzidos em comunicação efetiva. A consciência linguística dos falantes "nada tem a ver com 
o sistema abstrato de formas normativas", mas sim com a linguagem enquanto "conjunto dos contextos possíveis de uso de cada forma particular" (BAKHTIN/ VOLOCHÍNOV, 2010, p. 98).

De acordo com Bakhtin (2006, p. 265), "a língua passa a integrar a vida através de enunciados concretos (que a realizam); é igualmente através de enunciados concretos que a vida entra na língua". Esses enunciados concretos, ainda segundo o autor, são modulados pelos gêneros do discurso, os quais são dados aos sujeitos quase da mesma forma que é dada a língua materna, cuja composição vocabular e estrutura gramatical provêm dos discursos que se ouvem e se reproduzem na comunicação viva entre os sujeitos.

Nesse sentido, aprender uma língua significa, para Bakhtin (2006), aprender a construir enunciados, uma vez que os sujeitos não falam por orações e palavras isoladas, mas sim por enunciados: os discursos são organizados pelos gêneros quase do mesmo modo que os organizam as formas gramaticais e sintáticas. Depreende-se, assim, que os textos orais, escritos ou sinalizados são produzidos por meio de determinados gêneros do discurso. Estes, trazendo formas típicas de construção, funcionam como uma forma de linguagem prescritiva orientando os sujeitos na produção e compreensão dos diferentes discursos em circulação social. (SCHNEUWLY, 2010)

Uma metodologia de ensino de língua que pressupõe o uso efetivo da linguagem entre sujeitos que agem em um processo vivo e concreto de interação, orientados discursivamente pelos diferentes gêneros, pode, assim, levar os aprendizes mais facilmente à percepção das determinações sociais da comunicação, do valor das unidades linguísticas e de seus diferentes recursos.

Para aplicar tal concepção à educação de surdos é necessário entender os caminhos percorridos por estes para a aquisição da escrita. Para chegar à escrita, o surdo reconstrói a história de sua relação com a linguagem por meio da língua de sinais. Nessa perspectiva, é preciso que o sujeito surdo vivencie a linguagem escrita da língua portuguesa e a coloque em diálogo com a língua de sinais "em sua dinâmica dialógica e interdiscursiva, a fim de que os processos socioculturais, históricos e ideológicos que lhes são constitutivos possam ser (re) significados" (LODI; BORTOLOTTI; CAVALMORETTI, 2014, p. 134). De acordo com as autoras, o modo adequado de favorecer esse processo é oferecer, aos alunos surdos, práticas de leitura e produção textual em Libras, para que esse conhecimento possa, posteriormente, ser colocado em diálogo com o português. Essas práticas, convergentes para a proposta educacional bilíngue, trazem como principal fundamento a língua de sinais como base linguística para o ensino e a 
aprendizagem do português escrito como segunda língua, considerando-se, além das particularidades e da materialidade da primeira língua, sua importância para a constituição socioideológica dos sujeitos surdos (LACERDA; LODI, 2014). Nesse contexto, as relações do aluno surdo com a linguagem escrita devem, de acordo com Lodi (2013), se desenvolver a partir da leitura, considerando os discursos construídos anteriormente em Libras, uma vez que a leitura garantirá a esse aluno a percepção do texto em suas formas linguísticas e também seus diferentes modos de enunciar na segunda língua.

A atividade de produção escrita, no parecer de Lodi $(2013,179)$, pressupõe "o desenvolvimento de linguagem e conhecimento de como se produz textos", habilidades e competências desenvolvidas a partir de práticas de leitura e leitura enquanto trabalho reflexivo que possibilite a apreensão e a compreensão de aspectos implícitos e explícitos de um texto. Ora, isso só será possível se tal leitura for tomada como "um processo de compreensão ativa" em que "os múltiplos sentidos em circulação no texto" sejam constituídos a partir das relações dialógicas que se estabelecem entre texto, autor, leitor e as múltiplas vozes presentes nos textos. Aqui, a aprendizagem dos diferentes enunciados toma como base a Língua de Sinais "para a compreensão e significação dos processos socioculturais, históricos e ideológicos que perpassam" a Língua Portuguesa escrita (LODI, 2004, p.31). Tais enunciados, ainda de acordo com Lodi (2013), terão de início a forma de enunciar em Libras e, aos poucos, por meio de relações interdiscursivas e interlinguísticas, se transformam em enunciados que atendem aos processos enunciativos da Língua Portuguesa.

\section{PORTUGUÊS PARA SURDOS EM AMBIENTE INTERACIONAL DE OFICINAS}

Buscando-se colocar em prática uma metodologia de ensino de Língua Portuguesa para surdos como segunda língua a partir da interação verbal, conforme proposta neste trabalho, oficinas foram desenvolvidas durante os anos de 2013 e 2014 com um grupo de surdos egressos ou em fase final do ensino médio e por alunos dos anos finais do ensino fundamental. Os sete participantes surdos que frequentaram as oficinas, denominados para fins da pesquisa de Denis, Dalton, Wilson, Wesley, Janaína, Miguel, e Júlia, identificados, nas transcrições e análise dos dados, como participantes surdos P1, P2, P3, P4, P5, P6 e P7, respectivamente, traziam, em comum, histórias de um modelo escolar que, não atendendo às necessidades específicas em seu processo de alfabetização, acabou estabelecendo limitações em relação à leitura e à escrita em português. É importante salientar 
que o processo de alfabetização da maioria desses sujeitos surdos não ocorreu em circunstâncias favoráveis, uma vez que não vivenciaram o português como segunda língua e nem contaram com o apoio de interlocutores em língua de sinais.

As oficinas foram coordenadas por um dos autores deste trabalho, contando com a participação de pesquisadores da área da surdez, aqui denominados Educadores, os quais serão reconhecidos por Luna (E1), Milena (E2), Danilo (E3), Adriano (E4) e Katy (E5), quando da transcrição, apresentação e análise dos dados.

Respondendo a propostas de educação bilíngue para surdos, as oficinas se configuraram a partir de um trabalho de leitura e de reescrita da história de aventura As sete viagens de Simbad, o marujo (HOLEINONE, 1998), privilegiando interações discursivas em Libras. Considerando que as relações do sujeito surdo com a escrita devem ser desenvolvidas a partir da leitura e dos discursos construídos anteriormente em língua de sinais, ou seja, do conhecimento do gênero a ser produzido primeiramente na língua de sinais (LODI, 2013), criou-se um material didático, com a elaboração de um vídeo, em Libras, da referida história de aventura, narrada por um dos educadores ouvintes.

As atividades das oficinas desenvolveram-se a partir de um trabalho que levou os participantes surdos a conhecerem a linguagem e os aspectos composicionais constitutivos dos gêneros discursivos de uma história de aventura por meio do vídeo em Libras. Após o trabalho realizado com o vídeo que garantiu aos participantes surdos transitarem pela história na língua de sinais, procedeu-se à atividade de leitura do texto escrito.

Os procedimentos de leitura propostos em Língua Portuguesa levaram em conta a contextualização do tema e de palavras, buscando, de acordo com Lodi (2013), o diálogo entre Libras e situações do cotidiano, uma vez que os alunos surdos já traziam, de seu ambiente escolar e extraescolar, o contato com o português escrito. Os problemas relacionados à recepção do texto escrito foram enfrentados em um exercício de leitura em grupo, proporcionado pelo texto digitalizado e projetado pelo data show. Assim, apoiando-se na enunciação um do outro e nos enunciados em Libras e Língua Portuguesa escrita, juntos buscavam, pela mediação dos educadores, compreender o texto escrito em seu lócus e contextos correspondentes. Durante as atividades de leitura, observou-se que as ações de permuta entre os participantes surdos e as intervenções formalizadas tornaram-se indispensáveis para a organização da aprendizagem do texto quanto aos modos de enunciação em outra língua. Tendo em vista que o usuário de uma língua se serve dela para suas necessidades enunciativas, fazendo uso de suas formas normativas em contextos precisos (BAKHTIN/ VOLOCHÍNOV, 2010), a preocupação, na atividade de 
leitura, foi levar os participantes surdos a perceberem o traço distintivo das novas significações que as formas linguísticas adquirem em enunciações particulares.

Assegurando aos participantes surdos uma aproximação com o texto escrito enquanto nova forma de enunciar e de enfrentar outras formas linguísticas, a leitura abriu caminhos para novo enfrentamento: a escrita. Esta se configurou por meio da reescrita a várias mãos da história de aventura estudada, propondo-se que os surdos narrassem em Libras a história lida para que outros surdos a registrassem em português escrito. Tal atividade tomou como base a noção de linguagem enquanto atividade dinâmica em um processo de construção e troca de conhecimentos por meio da interação entre os sujeitos.

A reescrita, como materialização do processo de construção de sentidos a partir dos contextos manipulados anteriormente pela leitura, proporcionou aos participantes surdos a oportunidade de colocarem em jogo os conhecimentos construídos, comparando, contrastando, transformando e experimentando novos modos de construção. Compartilhando o modo de realização de uma produção textual escrita, os participantes surdos compuseram juntos os conhecimentos sobre essa linguagem. O exercício Libras/Língua Portuguesa (na qual os surdos narram em Libras para que outros surdos registrem em português escrito) propiciou a afinação dos recursos característicos do gênero e do código próprio do registro escrito.

As atividades das oficinas foram videogravadas por uma auxiliar de pesquisa e posteriormente, traduzidas. O processo de videogravação também permitia que o texto produzido em conjunto e escrito na lousa fosse reapresentado na oficina subsequente para a continuidade dos trabalhos de reescrita. Para a continuidade deste trabalho, previa-se ainda a reapresentação da história em Libras, não só para contextualizar os participantes que porventura tivessem faltado à oficina anterior, com também para reatar o fio da história do trecho a ser reescrito.

\section{AS OFICINAS: ANALISANDO OS DADOS}

Pretende-se, a partir dos episódios eleitos para esta análise, apresentar sequências interlocutivas referentes à reescrita e à reelaboração textual coletiva pelos surdos. Os episódios traduzidos serão apresentados em cenas, de modo a exibir os aspectos interdiscursivos constitutivos do decurso das interações, bem como os elementos que nortearam o trabalho coletivo dos participantes surdos.

Buscando estabelecer valores qualitativos do trabalho de linguagem, levantaremos aspectos do desenvolvimento dos participantes em direção à construção de autonomia no processo de produção textual escrita, ao longo das 
oficinas analisadas como locus de interação e aprendizagem. Focando os aspectos linguísticos como eixo de análise, trataremos do funcionamento da língua em uso e de sua sistematização.

Nesse sentido, percorreremos as cenas que perfazem o corpus do presente artigo rastreando episódios que desvelaram o trabalho dos participantes surdos nas soluções de questões organizacionais, desde a semântica até a estrutura sintática, estendendo-se para o planejamento textual e discursivo. Assim, dentre os aspectos linguísticos abordados na pesquisa, destacaremos exemplos pertinentes à coesão e à coerência, aos aspectos verbais e ao uso da preposição e do adjetivo. Tal relação, sem vincular-se a uma ordem lógica de problematização, foi colhida no fluxo das oficinas em episódios que valorizaram a reflexão dos participantes surdos sobre a língua escrita. Vale lembrar que os aspectos aqui exibidos não se dão isoladamente; todavia, para efeito de análise, segmentamos em subitens para mostrar como os participantes surdos lidaram com padrões e estruturas da língua escrita no processo da construção textual.

As cenas apresentadas a seguir, trazem as elaborações, reelaborações, busca de soluções e sistematizações da/para língua, explorando as vias tomadas pelos participantes surdos. Para a transposição e apresentação dos dados deste trabalho, foi utilizado um quadro com 4 colunas: Quem sinaliza, Tradução, Para quem sinaliza e Texto escrito produzido pelos participantes surdos. Considerou-se, nesse processo de tradução, a modalidade gesto-visual da Língua de Sinais, tendo em vista a necessidade de esclarecer ao leitor determinadas rotas utilizadas pelos participantes surdos quando de suas enunciações. Assim, por exemplo, quando estes e educadores ouvintes se valeram da datilologia, tais palavras foram grafadas em caixa alta e separadas por hífen.

\subsection{Coesão e coerência}

Buscaremos no recorte da cena, a seguir, sinais que revelem as soluções apresentadas pelos participantes surdos para imprimirem sentido a seus textos. A cena 1, apresentada a seguir, refere-se ao episódio em que Simbad, "o carregador", ao adentrar as portas de um palácio avista um grupo de homens elegantes sendo servidos por pajens, que lhes ofereciam bebidas e doces. À sinalização dos parceiros, o escriba registra o texto. 
Quadro 1. Cena 1 - escriba: P2

\begin{tabular}{|c|c|c|c|}
\hline $\begin{array}{l}\text { Quem } \\
\text { sinaliza }\end{array}$ & Tradução & $\begin{array}{l}\text { Para quem } \\
\text { sinaliza }\end{array}$ & $\begin{array}{l}\text { Texto escrito produzido pelos } \\
\text { participantes surdos }\end{array}$ \\
\hline P3 & O pajem servia. & $\mathrm{P} 2 / \mathrm{E} 2 / \mathrm{E} 4$ & \\
\hline $\mathrm{P} 4$ & P-A-J-E-N-S, pajens serviam. & $\mathrm{P} 2 / \mathrm{E} 2 / \mathrm{E} 4$ & \\
\hline P3 & Certo & $\mathrm{P} 2 / \mathrm{E} 2 / \mathrm{E} 4$ & $\begin{array}{l}\text { Ele viu os homens com roupas } \\
\text { elegantes e pajens dando doces e } \\
\text { bebidas as pessoas }\end{array}$ \\
\hline n........... & 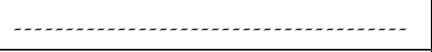 & (n........ & (n) \\
\hline E3 & $\begin{array}{l}\text { Estas "pessoas" aqui são esses } \\
\text { "homens" aqui. Entenderam? }\end{array}$ & Todos & \\
\hline n.......... & (1) & & \\
\hline P3 & $\begin{array}{l}\text { Só trocar, inverter as palavras, } \\
\text { mudar, não sei. }\end{array}$ & $\begin{array}{l}\text { P2 } \\
\text { (reescreve) }\end{array}$ & $\begin{array}{l}\text { Ele viu os homens com roupas } \\
\text { elegantes e pajens dando doces e } \\
\text { bebidas os homens }\end{array}$ \\
\hline n.............. & - non & (n.......... & nan \\
\hline E4 & $\begin{array}{l}\text { A palavra homens lá no quadro, } \\
\text { de novo, como? }\end{array}$ & Todos & \\
\hline P1 & Não sei. & Todos & \\
\hline E2 & $\begin{array}{l}\text { Ele viu o grupo dos homens, em } \\
\text { português não podemos repetir } \\
\text { as palavras, como podemos } \\
\text { melhorar essa escrita? Por qual } \\
\text { palavra podemos trocar? }\end{array}$ & Todos & \\
\hline P5 & A eles. E-L-E-S. & $\mathrm{P} 2 / \mathrm{E} 2 / \mathrm{E} 3$ & $\begin{array}{l}\text { Ele viu os homens com roupas } \\
\text { elegantes e pajens dando doces e } \\
\text { bebidas a eles }\end{array}$ \\
\hline
\end{tabular}

Fonte: Autores

Nesse evento, podemos acompanhar como a coerência textual foi enfrentada pelos participantes surdos a partir de questões de referenciação envolvendo o seguinte período: Ele viu os homens com roupas elegantes e pajens dando doces e bebidas as pessoas ${ }^{1}$. Após as discussões que levaram os participantes surdos a entenderam que o termo "pessoas" se referia aos "homens com roupas elegantes", P2 o substitui por "os homens". Sem ainda saber utilizar o elemento coesivo adequado responsável pela reativação do referente "homens elegantes", P2 se vale da recorrência do termo para manter a coerência textual. Alertados por E4, os

1. Em arial aparece o texto escrito pelos Participantes Surdos. 
participantes percebem a repetição da palavra homem no texto, porém, $\mathrm{P} 1$ admite não ter a solução. Esta vem de P5 que sinaliza "A eles", reconfigurando coerentemente o enunciado. A tentativa de $\mathrm{P} 2$ no reestabelecimento da cadeia coesiva pela repetição de palavras assemelha-se a estratégias utilizadas por escritores iniciantes. Todavia, aqui há que se considerar seu esforço, uma vez que na língua de sinais os discursos manifestam-se espacialmente, dispondo ali as personagens para referências de uma enunciação. Apesar de lançar mão de uma atividade de inferência que foge às normas gramaticais do português, o escriba consegue organizar o texto escrito. São, pois, esses experimentos que permitem a familiarização dos participantes surdos com as categorias sintáticas do discurso escrito.

\subsection{Aspectos verbais}

Os aspectos verbais agora tratados nos remetem às relações que os participantes surdos travaram com questões de ordem sintática, estrutural e discursiva, às voltas com processos de compreensão, adequação e construção de sentido.

A busca de melhores modos de dizer, como indicativo de individualidade do falante no emprego da língua, pode ser observada na cena 2 a seguir, em que os participantes surdos discutem a seleção da forma verbal, exibindo um trabalho de adequação que envolve o texto tanto em sua organização quanto em seu funcionamento enunciativo. O episódio refere-se ao momento da história em que, após ancorarem em uma ilha, os tripulantes do navio acendiam o fogo para cozinhar.

\section{Quadro 2. Cena 2- escriba P6 e P2}

\begin{tabular}{|l|l|l|l|}
\hline $\begin{array}{c}\text { Quem } \\
\text { sinaliza }\end{array}$ & \multicolumn{1}{|c|}{ Tradução } & \multicolumn{1}{|c|}{$\begin{array}{c}\text { Para quem } \\
\text { sinaliza }\end{array}$} & \multicolumn{1}{|c|}{$\begin{array}{c}\text { Texto escrito produzido pelos } \\
\text { participantes surdos }\end{array}$} \\
\hline P1 & $\begin{array}{l}\text { Não é fazer fogo, você precisa } \\
\text { colocar que é acender, entendeu? }\end{array}$ & P2 & $\begin{array}{l}\text { Chefe navio aviso jogar ancora água, } \\
\text { depois as pessoas descembarcar ilha } \\
\text { faz fogo, depois ouvir grito }\end{array}$ \\
\hline$\ldots$ & $\ldots \ldots \ldots$ & $\ldots \ldots$ \\
\hline P2 & $\begin{array}{l}\text { A pessoa, não, espera, foi o } \\
\text { homem que acendeu o fogo? } \\
\text { Quem foi? }\end{array}$ & P6 & \\
\hline
\end{tabular}




\begin{tabular}{|c|c|c|c|}
\hline P6 & S-I-M-B-I-A...Não...S-I-M-B-I-D & $\begin{array}{lr}\text { P2 } & \text { (E3 } \\
\text { sugere } & \text { que } \\
\text { se } & \text { coloque } \\
\text { o } & \text { ponto } \\
\text { final após } \\
\text { "desembarcar } \\
\text { ilha". P2 } \\
\text { decide apagar } \\
\text { o restante } \\
\text { da frase para } \\
\text { reescrevê-la). }\end{array}$ & $\begin{array}{l}\text { Dono de navio aviso jogar a } \\
\text { ancora na água, depois as pessoas } \\
\text { descembarcar ilha. }\end{array}$ \\
\hline P2 & O H-O-M-E-M & P6 & \\
\hline $\mathrm{P} 2$ & Fogo... O A-C-E-N-D-E-U & P6 & O homem acendeu o fogo. \\
\hline
\end{tabular}

Fonte: autores

O texto produzido pelos participantes até então trazia a ideia de que as pessoas que desembarcaram na ilha "fizeram fogo". Embora a adequação verbal sugerida por P1 "Não é fazer fogo, você precisa colocar que é acender, entendeu?" tenha marcas de preferências, uma vez que a forma "fazer fogo" é cabível no contexto, traz a língua para o plano de seu funcionamento social, histórico e cognitivo. Ou seja, os sentidos das expressões se produzem situadamente e as escolhas dessas expressões se vinculam às experiências do sujeito enunciador. $\mathrm{E}$, em se tratando de um sujeito surdo às voltas com uma língua diferente da sua, demonstra um trânsito para a autonomia de expressão na língua escrita. A linguagem, de acordo com Franchi (1987, p. 12), é um trabalho por meio do qual, "histórica, social e culturalmente, o homem organiza e dá forma a suas experiências". Assim, conclui o autor, é na interação social que os sujeitos se apropriam do sistema linguístico, não só reproduzindo, mas também ativando esquemas prévios em um trabalho de reconstrução conjunta e partilhada dos objetos linguísticos dos quais se utilizam. A seleção de formas dentro das diferentes possibilidades da língua tem seu reflexo no processo de desenvolvimento da linguagem uma vez que a busca de formas de dizer mais adequadas e elaboradas para diferentes contextos revela maturidade linguística em construção. Assim, aos poucos, os participantes surdos deixam o domínio cristalizado sinal/palavra ou conceito/palavra para buscarem a pluralidade de modos de dizer e melhores modos de dizer. E buscar melhores modos de dizer em diferentes situações contextuais é demonstrativo de uso efetivo da língua, uma vez que a constroem orientando-se por uma enunciação concreta e precisa.

A seguir, na cena 3 , diferentes percepções e representações de mundo definem a utilização do verbo afogar. $\mathrm{O}$ trecho a ser reescrito pelos participantes 
surdos se relacionava ao episódio em que, após o desembarque em uma suposta ilha, Simbad não consegue voltar ao navio.

\section{Quadro 3. Cena 3: escriba P2 e P6}

\begin{tabular}{|c|c|c|c|}
\hline $\begin{array}{l}\text { Quem } \\
\text { sinaliza }\end{array}$ & Tradução & Para quem sinaliza & $\begin{array}{c}\text { Texto escrito produzido } \\
\text { pelos participantes surdos }\end{array}$ \\
\hline E2 & $\begin{array}{l}\text { Simbad não conseguiu voltar } \\
\text { para o navio, ele fez o que? O } \\
\text { que aconteceu? }\end{array}$ & Todos & \\
\hline P1 & Ele pulou no mar. & E2 & \\
\hline E2 & Ele nadou e encontrou o quê? & Todos & \\
\hline $\mathrm{P} 1, \mathrm{P}_{2}, \mathrm{P} 5$ & Um barril & E2 & \\
\hline$\ldots \ldots$ & n........... & $\ldots \ldots$ & 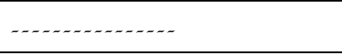 \\
\hline P2 & Afogar? & E2 & \\
\hline E2 & Afogar & P2 & \\
\hline $\mathrm{P} 2$ & É afogar & P6 & \\
\hline P6 & Ele abraça o barril? & $\mathrm{P} 2$ & \\
\hline P2 & Não, coloca A-F-O-G-A & $\begin{array}{l}\text { P6 (P6 se atrapalha e } \\
\text { P2 faz o registro). }\end{array}$ & Eu afoga \\
\hline P5 & $\begin{array}{l}\text { O quê? Apaga, ele não afogou, } \\
\text { não morreu. }\end{array}$ & $\mathrm{P} 2$ & \\
\hline P2 & Afogou sim, S-I-M & P5 & \\
\hline P5 & $\begin{array}{l}\text { Ele encontrou... Ele nadou } \\
\text { depois encontrou um barril. }\end{array}$ & $\mathrm{P} 2$ & \\
\hline P2 & Isso. & P5 & $\begin{array}{l}\text { Eu afoga depois encontrei } \\
\text { o barril }\end{array}$ \\
\hline
\end{tabular}

Fonte: Autores

Frente ao registro: Eu afoga, P5 contesta: "O quê? Apaga, ele não afogou, não morreu". Defendendo-se, P2 reafirma sua concepção: "Afogou sim, S-I-M". Tentando manter sua posição, P5 argumenta: "Ele encontrou... ele nadou, depois encontrou um barril". Concordando parcialmente com o raciocínio, P2 assente: "Isso". Todavia, a divergência de conceitos acaba levando os participantes surdos a um trabalho reflexivo ampliando os recursos para a construção de sentidos, uma vez que a conciliação se estabeleceu por meio do enunciado: "Eu afoga, depois encontrei o barril". A coerência foi enfim construída pelos interlocutores como resultado do intercâmbio entre aspectos textuais (verbais) e representacionais (mundo das 
ideias), expandido o conceito do verbo afogar. $\mathrm{O}$ embate consubstanciado em prática de linguagem evidenciou uma atividade cognitiva de leitura e de escrita, de produção e de recepção textual envolvendo diferentes percepções e representações de mundo.

\subsection{0 uso da preposição}

Pretende-se expor, na cena 4 a seguir, episódios protagonizados pelos participantes surdos que desvelam as operações concernentes às preposições por eles realizadas. Demarcando a função das preposições bem como seu processo de utilização na construção dos discursos, apontaremos as estratégias que estes participantes lançaram mão para construir e organizar suas experiências relativas a tal objeto linguístico.

Quadro 4. Cena 4 - escribas: P1 e P2

\begin{tabular}{|c|c|c|c|}
\hline $\begin{array}{l}\text { Quem } \\
\text { sinaliza }\end{array}$ & Tradução & $\begin{array}{c}\text { Para } \\
\text { quem } \\
\text { sinaliza }\end{array}$ & $\begin{array}{l}\text { Texto escrito produzido pelos } \\
\text { participantes surdos }\end{array}$ \\
\hline E2 & $\begin{array}{l}\text { Que palavra podemos colocar } \\
\text { entre "homem e roupas" para } \\
\text { melhorar essa escrita? }\end{array}$ & todos & $\begin{array}{l}\text { Ele viu os homens roupas elegante, } \\
\text { pajens dar doces e bebinda os pessoas }\end{array}$ \\
\hline P2 & $\begin{array}{l}\text { Viu o homem de roupa elegante, } \\
\text { é isso? }\end{array}$ & todos & \\
\hline E2 & Qual palavra colocar aqui? & todos & \\
\hline $\mathrm{P} 4$ & O-S? Não é? A-S? & E2 & \\
\hline P3 & Falta uma palavra A-S? A-S? & $\mathrm{P} 4$ & \\
\hline P2 & C-D-O...O-S & E1 & \\
\hline P5 & Ele viu homens C-O-M. & P1 & \\
\hline P3 & Isso, C-O-M! & P1 & $\begin{array}{l}\text { Ele viu os homens com roupas elegante, } \\
\text { pajens dar doces e bebinda os pessoas }\end{array}$ \\
\hline
\end{tabular}

Fonte: Autores

Significativa reflexão sobre o funcionamento de preposições se estabelece a partir da intervenção de E2 que induz os participantes surdos a melhorar o texto: "Que palavra podemos colocar entre homem e roupas para melhorar essa escrita?". O texto em seu caráter provisório pode se transformar, assim como se transformam os participantes frente a suas escolhas e tentativas de registro adequado. A sugestão 
de $\mathrm{P}$ 4, em forma de pergunta "O-S? Não é? A-S? ", alavancam as reflexões empreendidas por P2, P3 e P5. Em suas tentativas, ao mesmo tempo em que colocam em jogo seus saberes, ampliam o conhecimento de Língua Portuguesa, diferenciando os recursos com os quais sinalizam e escrevem. É, pois, nessa prática de diversidade que os fatos gramaticais da língua que buscam sistematizar, o português, se assentam. As intervenções provisórias lançadas pelos participantes surdos suscitaram, no outro, reflexões que reverberaram em si mesmos. A proposta acertada por P5 "Ele viu homens C-O-M", não surgiu sem um intenso exercício de construção coletiva de um fato linguístico que exigiu suposições e conjecturas concernentes à estrutura do português escrito.

Na cena 5 apresenta-se um trabalho de refacção textual empreendido pelos participantes surdos, também relacionado ao emprego da preposição, que demarca a parceria na construção do português.

Quadro 5. Cena 5 - escriba: P2

\begin{tabular}{|c|c|c|c|}
\hline $\begin{array}{l}\text { Quem } \\
\text { sinaliza }\end{array}$ & Tradução & $\begin{array}{c}\text { Para } \\
\text { quem } \\
\text { sinaliza }\end{array}$ & $\begin{array}{c}\text { Texto escrito produzido pelos participantes } \\
\text { surdos }\end{array}$ \\
\hline E3 & $\begin{array}{l}\text { Vamos corrigir...Certo? } \\
\text { Tem mais? }\end{array}$ & & $\begin{array}{l}\text { O simbad encontrou ilha verdade depois } \\
\text { encontrou o cavalo égua marado com a corda. }\end{array}$ \\
\hline E3 & $\begin{array}{l}\text { simbad encontrou (E3 } \\
\text { aponta para o termo "ilha } \\
\text { verdade") }\end{array}$ & todos & $\begin{array}{l}\text { O simbad encontrou ilha verdade depois } \\
\text { encontrou o cavalo égua marado com a corda. }\end{array}$ \\
\hline P1 & $\begin{array}{l}\text { Precisa colocar } \\
\text { preposição, precisa } \\
\text { colocar preposição, } \\
\text { conhece? Preposição }\end{array}$ & E3 & \\
\hline P2 & Conhece? & E2 & \\
\hline P1 & $\begin{array}{l}\text { Precisa colocar A-O- U, } \\
\text { P-A-R-A, D-E, N-O. }\end{array}$ & todos & \\
\hline $\mathrm{P} 2$ & U-M & todos & \\
\hline $\mathrm{P} 1$ & Falta colocar as palavras & todos & \\
\hline $\mathrm{P}_{2}$ & $\begin{array}{l}\text { Pensa U-M-A ... eu acho } \\
\text { que é UMA aqui }\end{array}$ & E3 & $\begin{array}{l}\text { O simbad encontrou uma ilha verdade depois } \\
\text { encontrou o cavalo égua marado com a corda. }\end{array}$ \\
\hline E3 & Esta certo? & todos & \\
\hline $\mathrm{P} 1$ & $\begin{array}{l}\text { Coloca o N-A... coloca o } \\
\text { N-A, não é verdade? É? }\end{array}$ & todos & \\
\hline$\ldots \ldots$ & - מ. & $\ldots \ldots$ & $\ldots$ \\
\hline
\end{tabular}




\begin{tabular}{|c|c|c|c|}
\hline P2 & Coloca o D & E3 & \\
\hline ...... & 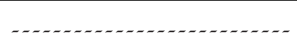 & $\ldots . .$. & - \\
\hline P2 & Coloca o D-E & & $\begin{array}{l}\text { O simbad encontrou uma ilha de verdade } \\
\text { depois encontrou o cavalo égua marado com } \\
\text { a corda. }\end{array}$ \\
\hline
\end{tabular}

Fonte: Autores

Nessa cena, temos uma demonstração pontual de amadurecimento sobre questões gramaticais caracterizando certa familiaridade dos participantes surdos com fatos da língua concernentes à preposição. Ao apontar para o sintagma nominal "ilha verdade", E3 desperta imediatamente em P1 a consciência da falta da preposição: "precisa colocar preposição, precisa colocar preposição, conhece? Preposição?". A sequência que se desenrola até a solução dada por P2 "coloca o DE", está carregada de reflexões sobre a linguagem aplicada ao texto escrito. Ou seja, está permeada por tentativas partilhadas e por construções de hipóteses revelando que o sujeito não é somente aquele que se apropria do sistema de escrita, mas aquele que constrói na parceria como outro e abre possibilidades de (re)formulação (FRANCHI, 1987). Tentando estabelecer uma relação entre os dois termos, os participantes surdos se exercitaram entre possíveis variáveis, aventurando-se no que já sabiam do português (combinando ou contraindo artigos e preposições). A dificuldade em lidar com preposições é uma dificuldade natural de quem aprende outra língua, pois, diferentemente dos substantivos, adjetivos e advérbios que carregam conteúdos em si (palavras lexicais), as preposições não carreiam um significado explícito (palavras gramaticais). Porém, mesmo levando em conta essa dificuldade, observase que P1 se valoriza como um sujeito de escrita ao questionar o educador em relação aos conhecimentos deste sobre preposição. De certa forma, a posição de empoderamento licencia P1 a operar livremente com hipóteses, mesmo que estas ainda não satisfaçam às exigências gramaticais.

$\mathrm{Na}$ cena 4, a questão da preposição já havia sido enfrentada, porém, sem adentrar valores categoriais e de nomenclatura. No dizer de Franchi (1987, p. 39), "é no longo exercício de operação sobre a linguagem e a língua que se pode compreender melhor a função da morfologia na sintaxe", e, consequentemente "o valor categorial dos diferentes papéis que os elementos desempenham" nas estruturas sintáticas. Fazendo uso das palavras do autor, concluímos que antes de saber o que é uma preposição é necessário "ter-se servido efetivamente dessas distinções gramaticais no trabalho de construção e reconstrução das expressões". São essas atividades epilinguísticas que tornam ativo o conhecimento que os aprendizes trazem de outras experiências, abrindo-lhes as portas para a sistematização gramatical para 
que um dia se possa falar em atividade metalinguística (FRANCHI, 1987). No episódio relatado podem-se ver avanços na capacidade dos participantes surdos quanto à diversificação dos recursos com os quais sinalizam e escrevem, colocando em prática um fato gramatical (preposição) como sinal da diversidade das línguas aí envolvidas.

\subsection{0 uso do adjetivo}

Investigamos a ocorrência de adjetivo na produção escrita dos participantes surdos para além de aspectos meramente gramaticais, voltando-nos para dimensões discursivas, ou seja, vamos nos voltar também para o viés da construção de sentido. Para a produção do texto, os participantes surdos procederam a uma seleção lexical e gramatical na tentativa de imprimir determinados sentidos que correspondessem à situação de comunicação por eles enfrentada.

A cena a seguir nos reporta ao episódio após o naufrágio, quando Simbad encontra uma ilha verdadeira com a ajuda de um barril.

Quadro 6. Cena 6 - escriba P2

\begin{tabular}{|c|c|c|c|}
\hline $\begin{array}{l}\text { Quem } \\
\text { sinaliza }\end{array}$ & Tradução & $\begin{array}{l}\text { Para quem } \\
\text { sinaliza }\end{array}$ & $\begin{array}{l}\text { Texto escrito produzido pelos partici- } \\
\text { pantes surdos }\end{array}$ \\
\hline P5 & $\begin{array}{l}\text { Ele encontrou... Ele nadou } \\
\text { depois encontrou um barril. }\end{array}$ & $\mathrm{P} 2$ & \\
\hline $\mathrm{P} 2$ & Isso. & P5 & Eu afoga depois encontrei o barril \\
\hline ב....... & 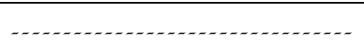 & (n........... & $\ldots$ \\
\hline P5 & Isso, está certo. & P2 & \\
\hline P6 & $\begin{array}{l}\text { Ele abraçou o barril, ele } \\
\text { abraçou o barril, né? }\end{array}$ & $\mathrm{P} 2$ & $\begin{array}{l}\text { Eu afoga depois encontrei o barril e } \\
\text { vento bom, achei uma ilha. }\end{array}$ \\
\hline
\end{tabular}

Fonte: Autores

O evento discutido trata da utilização do adjetivo "bom" materializado no texto por seu caráter de necessidade para a consecução do desfecho de um episódio. É assim que a enunciação de P2 se configura em texto concreto: Eu afoga depois encontrei o barril e vento bom, achei uma ilha. O sintagma "vento bom" se desdobra quanto ao significado, uma vez que o substantivo vento qualificado com o adjetivo bom representa a salvação de Simbad, o marujo, que fora levado pelo vento e pela correnteza a uma ilha de verdade. $\mathrm{O}$ adjetivo bom, ainda, antecipa a situação favorável de Simbad ao chegar à ilha e encontrar acolhida junto ao cavalariço do rei. Neste sentido, o adjetivo agrega historicidade, estabelecendo uma relação de 
natureza discursiva entre a situação de Simbad e aquela circunstância. $\mathrm{O}$ adjetivo foi empregado não como mero qualificador, mas como valoração discursiva uma vez que, além de influenciar a enunciação, é determinante para aquele contexto. $\mathrm{O}$ fato aponta para um amadurecimento do modo como P2 se organiza para acionar os mecanismos necessários para acessar determinada enunciação.

A análise nos permite recuperar o desempenho do participante surdo no tratamento dos adjetivos, quando busca determinado expediente para resolver questões de comunicação, dando prova de maior domínio do funcionamento linguístico na construção de sentidos em outra língua.

\section{CONSIDERAÇOES FINAIS}

O processo da reescrita coletiva, em situação de oficinas, foi colocado neste trabalho como objeto de reflexão sobre as práticas e as formações discursivas que incidiram sobre a aprendizagem dos participantes surdos. Assim, acompanhamos a evolução destes participantes na organização da escrita, por decisões autônomas ou negociadas, desde a recuperação da sequência lógica por princípios de coesão e coerência, passando pelo estabelecimento da ordem sintática por adequação verbal de acordo com exigências discursivas e textuais, até o despertar para o uso consciente das preposições e dos adjetivos na resolução de questões de comunicação e de narratividade de seus enunciados.

Olhando a linguagem como lugar de confluência dialógica, seguimos as operações aí empreendidas constatando que as interações e a qualidade destas, mediadas pela língua de sinais, tiveram um papel imprescindível na construção dos processos linguísticos dos participantes surdos na escrita em português. As oficinas, ambiente interacional de aprendizagem, se definiram enquanto espaço de produção de linguagem, no qual os participantes surdos puderam se completar pela confluência das vozes de seus pares e dos educadores ouvintes.

Nesse sentido, a qualidade das interações propiciou a ressignificação de aspectos gramaticais, uma vez que os participantes surdos puderam refletir sobre a língua portuguesa escrita, tomando, aos poucos, a consciência de sua sistematização e funcionalismo. Atores da aprendizagem, estes participantes protagonizaram o ato de aprender, colocando em jogo os saberes construídos na experimentação e na troca. A escrita fez-se, então, na interação entre pares como um constante processo mediado pelo diálogo e nas tensões discursivas, pelos desdobramentos da prática linguística e não como mera assimilação da estrutura gramatical. Ou seja, a reflexão normativa do português escrito se deu pela interlocução no uso efetivo da língua. 
O processo revelou que a língua de sinais teve lugar de destaque nas relações travadas entre participantes surdos e o processo da escrita, constituindo-se como base para as buscas dos registros do texto escrito. Todavia, é importante salientar que não se acomodou com a escrita dos participantes surdos que trazia, de início, estruturas, funções e características próprias da língua de sinais. As atividades das oficinas apontaram para um trabalho de português padrão, ou seja, houve uma preocupação em desenvolver um trabalho sistematizado com a Língua Portuguesa para que a escrita destes participantes avançasse. Assim, para se enfrentar o cotidiano escolar do aluno surdo, são necessários o desenvolvimento e o aprimoramento de atividades voltadas ao contexto bilíngue que alavanquem sua aprendizagem da Língua Portuguesa escrita.

A experiência das oficinas aqui apresentada pode responder ao questionamento de professores sobre a possibilidade de seus alunos surdos aprenderem o português. Nesse sentido, o resultado desta experiência pode orientar o trabalho de professores que se interessam pelo trabalho com o aluno surdo em suas classes.

\section{$\overline{\text { REFERÊNCIAS }}$}

BAKHTIN, M. (1979). Os gêneros do discurso. In: Estética da criação verbal. 4. ed. Trad. Paulo Bezerra. São Paulo: Martins Fontes, 2006.

BAKHTIN, M. (VOLOCHÍNOV, V. N) (1895-1975). Marxismo e filosofia da linguagem: problemas fundamentais do método sociológico na ciência da linguagem, 14. ed. Trad. Michel Lahud e Yara Frateschi Vieira. São Paulo: HUCITEC, 2010.

FRANCHI, C. (1987). Criatividade e Gramática. Trabalbos em Linguística Aplicada, Campinas, n. 9 , p. 5-45.

HOLEINONE, P. (1998). As sete viagens de Simbad: o marujo e outras histórias. Trad. Denise Perrotti. São Paulo: Paulinas.

LACERDA, C.B.F.; LODI, A.C.B. (2014). A inclusão escolar bilíngue de alunos surdos: princípios, breve histórico e perspectivas. In: LODI, A.C.B.; LACERDA, C.B.F. (orgs). Uma escola, duas línguas: letramento em língua portuguesa e língua de sinais nas etapas iniciais de escolarização. 4. Ed. Porto Alegre: Editora Mediação, pp. 11-32.

LODI, A.C.B. (2004). A leitura como espaço discursivo de construção de sentidos: Oficinas com surdos. Tese de Doutorado em Linguística Aplicada e Estudos da Linguagem, Pontifícia Universidade Católica de São Paulo, São Paulo. 
LODI, A.C.B. (2013). Ensino da Língua Portuguesa como segunda língua para surdos: impacto na Educação Básica. In: LACERDA, C.B.F.; SANTOS, L.F. (orgs). Tenbo um aluno surdo, e agora? Introdução à Libras e educação de surdos. 1. ed. São Carlos, SP: EDUFSCar, pp. 165-183.

LODI, A.C.B.; BORTOLOTTI, E.C.; CAVALMORETI, M.J.Z. (2004). Letramentos de surdos: práticas sociais de linguagem entre duas línguas/culturas. Bakbtiniana, Revista de estudos do Discurso, São Paulo, v. 9, n 2, p. 131-149, Ago./Dez. Disponível em: [http:// www.scielo.br/pdf/bak/v9n2/a09v9n2.pdf]. Acesso em: 21 set. 2017.

ROJO, R.; CORDEIRO, G.S. (2010). Apresentação - Gêneros Orais e Escritos como objetos de ensino: modo de pensar, modo de fazer. In: SCHNEUWLY, B.; DOLZ, J. e colaboradores, Gêneros orais e escritos na escola. 2. Ed. Trad. Roxane Rojo e Glaís Sales Cordeiro. Campinas, SP: Mercado de Letras, 2. ${ }^{\circ}$ edição, pp. 7-16.

SCHNEUWLY, B. (2010). Gêneros e tipos de discurso: considerações psicológicas e ontogenéticas. In: SCHNEUWLY, B.; DOLZ, J. e colaboradores. Gêneros orais e escritos na escola. 2. Ed. Trad. Roxane Rojo e Glaís Sales Cordeiro. Campinas, SP: Mercado de letras, pp. 19-34.

Recebido: 8/02/2019

Aceito: 5/06/2019

Publicado: 25/06/2019 